\title{
Pautas de comportamiento alimentario y adaptaciones progresivas en los apéndices auxiliares en Agostocaris bozanici y Barbouria yanezi (Crustacea: Decapoda: Caridea: Agostocarididae, Hyppolitidae)
}

\author{
Norms of feeding behavior and progressive adaptations in auxiliary appendages in \\ Agostocaris bozanici and Barbouria yanezi (Crustacea: Decapoda: Caridea: Agostocarididae, \\ Hyppolitidae)
}

\author{
Luis M. Mejía-Ortíz
}

Laboratorio de Bioespeleología y Carcinología, División de Desarrollo Sustentable, Universidad de Quintana Roo-Cozumel. Av. Andrés Quintana Roo s/n, 77640 Cozumel, Quintana Roo, México.

Correspondencia: luismejia@uqroo.mx

\begin{abstract}
Resumen. Existen varias características que evidencian las adaptaciones a la vida cavernícola en los crustáceos; las principales son: pérdida de visión, carencia de pigmentación, especialización de estructuras sensoriales y elongación de los apéndices ambulatorios. En consideración a que en la literatura se ha registrado la escasez del alimento como una fuerza evolutiva y que en las cuevas anquihalinas la principal fuente de energía se produce de la acción bacteriana, se realizó un análisis con ayuda de microfotografías para identificar las adaptaciones en los apéndices que los crustáceos de estos ambientes utilizan para comer, pereiópodos quelados y maxilípedos, considerando aquellas especies que viven exclusivamente en áreas con altos niveles de $\mathrm{H}_{2} \mathrm{~S}$ de estos sistemas. Los resultados muestran que Agostocaris bozanici tiene más setas sobre el propodio del tercer maxilípedo mientras que Barbouria yanezi las tiene más fuertes en este apéndice. Pero en el margen interno de los quelípedos de $A$. bozanici existe una especialización muy particular, ya que muestra una serie de setas largas que posiblemente las usa como una herramienta para separar los microorganismos, quizás ciliados, del sedimento. Se concluye que Barbouria yanezi se alimenta de partículas grandes del material en degradación de la selva tropical circundante, mientras que Agostocaris bozanici tiene una seta desarrollada para comer microorganismos que actúan en la descomposición de este material.
\end{abstract}

Palabras clave: especies cavernícolas, Barbouria, Agostocaris, setas.

\begin{abstract}
There are several adaptations shown by crustaceans to cave life; namely: vision loss, lack of pigmentation, specialization of sensory structures and elongation of ambulatory appendages. Since it has been mentioned in the literature that food scarcity is the evolutionary force and that in anchialine caves the main energy source is produced by bacteria, an scanning electron microscopy analysis was conducted to identify the adaptations in the appendages that these crustaceans use for feeding, chelate pereopods and maxillipeds, considering those species that live exclusively in zones that have high levels of $\mathrm{H}_{2} \mathrm{~S}$. The results show that Agostocaris bozanici has more setae on the propodus of the third maxilliped whilst Barbouria yanezi has stronger setae in this appendage. But along the inner margin of the chelipeds of $A$. bozanici is an interesting specialization with a series of long setae possibly used as a tool to separate microorganisms, maybe ciliates, from the sediment. The conclusions are that Barbouria yanezi eats large particulate material in degradation coming from the nearby tropical forest, while Agostocaris bozanici has a specialized seta to eat the microorganisms that decompose this material.
\end{abstract}

Key words: cave species, Barbouria, Agostocaris, setae.

\section{Introducción}

Los crustáceos son un grupo conspicuo en la mayoría de los cenotes de la península de Yucatán; ocupan el segundo lugar en cuanto al número de especies de

Recibido: 02 diciembre 2009; aceptado: 26 abril 2010 artrópodos cavernícolas hasta hoy conocidas en México y el primero en especies acuáticas en estos ambientes (Hoffmann et al., 1986; Mejía-Ortíz, 2008). El origen de estas especies presenta cierta polémica; sin embargo, la teoría más aceptada sostiene un origen marino (Creaser, 1938; Pearse, 1938; Iliffe, 1986), probablemente a partir de la fauna intersticial (Jefferson, 1976), aunque también 
suelen encontrarse algunos ejemplares cuyos parientes más cercanos son dulceacuícolas (Hobbs et al., 1977; Iliffe, 1993).

Entre los crustáceos presentes en los cenotes, revisten especial interés los habitantes de las zonas oscuras o cuevas que a través de su evolución han desarrollado diversas adaptaciones en el nivel específico, entre las que figuran desde las de tipo morfológico hasta las fisiológicas y etológicas (Jefferson, 1976; Culver et al., 1995). Todas estas modificaciones permiten conocer algunas particularidades acerca del grado de adaptación de las especies a su ambiente (Mejía-Ortíz y López-Mejía, 2005).

Morfológicamente, se encuentran algunos rasgos característicos en las especies cavernícolas que, sin embargo, no se presentan como regla general (Culver et al., 1995). Entre éstos se encuentran, inicialmente, la falta de pigmentación de los individuos y la reducción de los ojos, los cuales comprenden una de las peculiaridades más distintivas de los habitantes de estos ambientes. También es muy particular la reducción de las tallas corporales (Hobbs et al., 1977) y la retención de caracteres juveniles en adultos (Culver, 1982), ambos aspectos vinculados según los respectivos autores- con la escasez de alimento. La elongación y el cambio estructural de apéndices en estas especies se encuentra relacionada en alguna medida con la detección y captura de alimento (Hobbs et al., 1977; Gillieson, 1996); de la misma forma, se presenta en algunos casos como mecanismo de economía metabólica para el movimiento (Culver, 1982), sin olvidar el papel que tienen las bacterias en estos ambientes extremos con altos contenidos de ácido sulfhídrico para la transformación de materiales de alimentación de estos crustáceos. Sin embargo, una modificación de gran relevancia en este aspecto la presenta el número y tamaño de órganos sensoriales, los cuales se incrementan al aumentar el tamaño de los apéndices que los portan, sea por ampliación del área superficial o en la densidad de los mismos por unidad de área (Culver, 1982). Asimismo, en algunas especies se han identificado cambios adaptativos en la anatomía del cerebro, donde el lóbulo óptico disminuye en tamaño y se incrementa el de los receptores dinámicos de equilibrio, de los receptores de equilibrio estático y de los receptores de impulso táctil, entre otros (Culver, 1982).

En relación con las adaptaciones de tipo fisiológico, los animales de las cavernas han mostrado una reducción en el consumo de oxígeno cuando se les compara con especies epigeas relacionadas cercanamente, lo cual es causado por 3 factores principales: su adaptación a bajos niveles de oxígeno, la relativa constancia de las condiciones ambientales combinada con una falta de depredadores y la general escasez de alimento (Hüppop, 1985). También han sido identificadas diferencias en las concentraciones de los carbohidratos, lípidos y proteínas y la presencia de estructuras especializadas para reservas de lípidos, esto último como fuente de energía potencialmente utilizable (Mejía-Ortíz, 2005). Por su parte, etológicamente se encuentran ritmos de actividad menos evidentes (Culver et al., 1995; Gillieson, 1996) y una reducción en la agresividad intraespecífica (Culver et al., 1995). También se presentan cambios en la biología reproductiva y en el ciclo de vida de muchas especies. Limitándose exclusivamente a especies acuáticas, se puede mencionar una menor producción de huevos y un incremento en su tamaño, lo que sugiere una eclosión en estadios más avanzados y un menor número de estadios larvales; una producción anual de huevos más impredecible y una frecuencia de apareamiento reducida (Hobbs et al., 1977; Gillieson, 1996).

Este tipo de adaptaciones le brinda a las especies estigobias una serie de ventajas competitivas para la subsistencia en este medio. Al ser relativamente más estables que los superficiales, estos cuerpos de agua provocan que los individuos que los habitan sean más frágiles a los cambios en el ambiente; por tanto, las especies se encuentran más propensas a la extinción (Watson et al., 1997; Schmitter-Soto et al., 2002). Igualmente, la condición estenoica de esta fauna la hace más sensible a los cambios inducidos por las actividades del hombre, que incluyen desde la extracción de agua hasta la contaminación (Watson et al., 1997), razón por la cual su preservación reviste especial cuidado.

\section{Materiales y métodos}

Barbouria yanezi Mejia, Zarza y López, 2008 fue recolectada en el cenote Tres Potrillos el 12 de diciembre de 2004, y Agostocaris bozanici Kensley, 1988 en el cenote Xcan-Ha el 4 de abril de 2005; ambas en la isla de Cozumel (véase Yañez et al., 2008, para la descripción de los cenotes). Las setas de los organismos fueron analizadas en los pereiópodos quelados así como en los maxilípedos a través de microscopía electrónica de barrido (MEB), de acuerdo con lo propuesto por Garm (2004a, b). Posteriormente, para la observación de las pautas de comportamiento se recolectaron 10 animales de ambas especies el 30 de junio de 2008 y se mantuvieron en el Laboratorio de Bioespeleología y Carcinología de la Universidad de Quintana Roo, en completa oscuridad y observados con cámaras infrarrojas. A los animales en cautiverio se les administró alimento que consistió en carne molida envuelta en una malla, para observar los tiempos de latencia (tiempo que tardan en tomar el alimento), las diferentes pautas en la toma del alimento y los apéndices 
involucrados, así como su frecuencia y la forma de la ingesta definitiva.

\section{Resultados}

Barbouria yanezi. El dactilo del tercer maxilípedo presenta espinas apicales y está cubierto de setas tanto ventral como dorsalmente (Fig. 1A). En la figura 1B se puede observar que además de las espinas apicales contiene setas que están cubiertas por expansiones cuticulares en la parte proximal (Fig. 1C). También dispone de una agrupación de setas en la parte dorsal del dactilo (Figs. 1D, E) y las setas que cubren a esta estructura se caracterizan por estar aserradas a lo largo de su extensión (Figs. 1F,G). La quela del segundo pereiópodo presenta un conjunto de setas aserradas largas en el ápice del propodio y el dactilo, así como en la porción superior de la articulación entre el dactilo con el propodio (Figs. 2A, C). En la superficie interna del dactilo, adyacente al borde cortante, se presenta una hilera de setas individuales (algunas en pares) simples, las cuales se caracterizan por presentar expansiones cuticulares en $\operatorname{los} 2 / 3$ posteriores (Fig. 2B). En la porción interna del propodio se presenta una hilera de setas aserradas las cuales se encuentran en grupos de 4; estas setas presentan sétulas aserradas a manera de escamas, dispuestas en hileras a lo largo de los 2/3 posteriores de su superficie y un poro terminal en su ápice (Figs. 2D, E).

Pautas registradas del comportamiento alimentario. Luego de incorporar alimento (carne molida) al sistema, los animales observados tardaron en promedio 20 min en tomarlo, para lo cual utilizaron los primeros pereiópodos sólo para sostenerlo: una vez hecho esto, dieron pequeñas probadas a la carne con ayuda de los maxilípedos en un promedio de tiempo de $3 \mathrm{~min}$, para posteriormente dedicarse a la ingesta utilizando los segundos pereiópodos y los maxilípedos para rasgar la carne y llevársela a la mandíbula (Fig. 3).

Agostocaris bozanici. El tercer maxilípedo tiene todo el dactilo cubierto de setas (Fig. 4A), pero en la parte apical cuenta con una espina que en su acercamiento se puede observar que está compuesta por cutículas (Fig. 4B), en cambio las setas de la parte más al centro del dactilo (Fig. 4C) tienen una terminación plumosa (Fig. 4D) o aserrada (Fig. 4E). Una de las características distintivas es el tipo de articulación del propodio con el carpo y del dactilo con el propodio, que se puede observar en la quela del primer pereiópodo (Fig. 5C). En primera instancia, es notable la presencia de numerosos dentículos, estrechamente distribuidos, en el margen cortante tanto del propodio como del dactilo (Fig. 5D). Bastante desarrolladas son las largas setas -al parecer simples pero muy robustas- presentes en la porción dorsal del dactilo y que se ubican en posición posterior al eje de articulación del dactilo con el propodio (Fig. 5D). Por último, se observa una hilera de setas simples regularmente espaciadas en el margen interno del propodio cuya articulación es infracuticular (Fig. 5F). La quela del segundo pereiópodo de $A$. bozanici se encuentra densamente poblada de setas simples, tanto en la superficie del propodio como del dactilo (Fig. 5A). En estos 2 artejos, las setas se encuentran ubicadas principalmente en la porción apical de los márgenes, externo en el propodio y cortante en el dactilo (Fig. 5B).

Pautas registradas. del comportamiento alimentario. $\mathrm{Al}$ incorporar alimento (carne molida) al sistema, los animales observados tardaron en promedio 10 min en tomarlo, para lo cual utilizaron el segundo par de pereiópodos sólo para sostenerlo por primera ocasión. Una vez hecho esto, con ayuda del primer pereiópodo raspan el alimento tantas veces como pueden. Este proceso les lleva $10 \mathrm{~min}$ en promedio entre la toma del alimento y la ingesta definitiva, que la realizan utilizando los maxilípedos tomando del primer pereiópodo los restos de carne para llevárselos a la mandíbula con ayuda de la seta terminal del maxilípedo (Fig. 6).

\section{Discusión}

Es necesario tener en cuenta que los crustáceos cavernícolas muestran tanto evolución constructiva como regresiva, que tienen influencia diferente en la selección natural. La evolución regresiva es la reducción o pérdida de algunas estructuras en los organismos durante su evolución; también ha sido llamada adaptación regresiva, reducción estructural o adaptación no constructiva (Culver, 1982; Lincoln et al., 1982; Banister, 1984; Kane y Richardson, 1985; Mejía-Ortíz y Hartnoll, 2005; Mejía-Ortíz y LópezMejía, 2005; Mejía-Ortíz et al., 2006).

En varios organismos de cuevas, las adaptaciones progresivas incluyen: el alargamiento de los apéndices sensoriales, ambulatorios y gnatales, y mayor presencia de setas en el cuerpo que incrementan su capacidad químico receptora (Allegrucci et al., 1992; Jones et al., 1992; Turk et al., 1996); el desarrollo de estructuras especializadas para el almacenamiento de los lípidos en el hepatopáncreas (Vogt y Štrus, 1992, 1999); el crecimiento de la yema en los huevos para extender el periodo de incubación y disminuir los estados larvales después de la eclosión (Poulson y White, 1969; Wilkens, 1985; Ueno, 1987; Wilkens, 1992; Culver et al., 1995; Gillieson, 1996; Mejía-Ortíz et al., en prensa); el aumento en la orientación espacial (Kellie et al., 2001; Li y Cooper, 2001, 2002) y en la eficiencia alimentaria (Abele y Felgenhauer, 1985). 

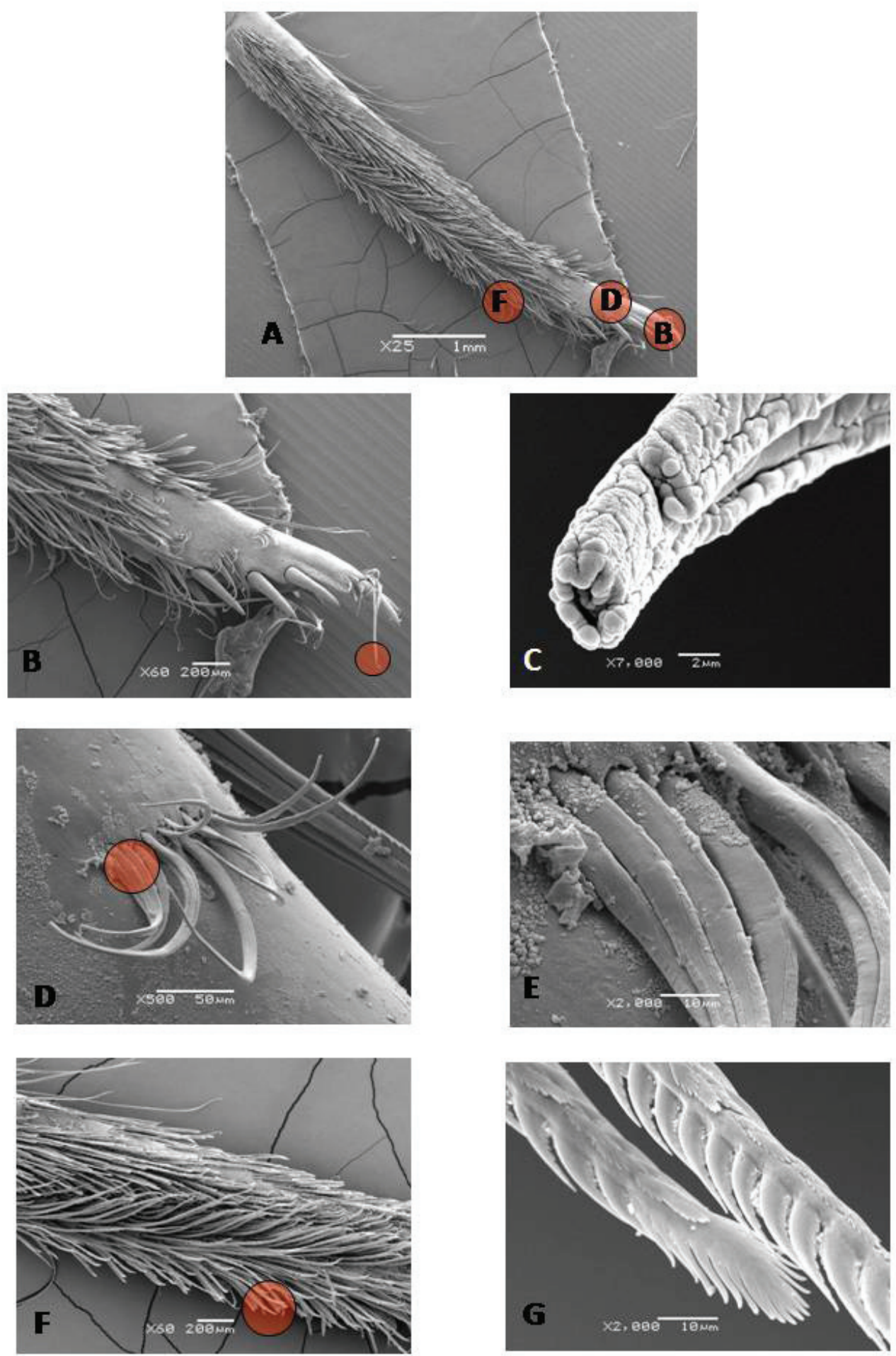

Figura 1. Análisis con MEB del dactilo del tercer maxilípedo de Barbouria yanezi: A, tercer maxilípedo; B, amplificación de la punta; C, acercamiento de la seta de la misma zona; D, amplificación de las setas de la parte dorsal del dactilo; E, acercamiento del arreglo de este conjunto de setas; F, amplificación de la parte lateral del dactilo, y G, acercamiento de la punta de las setas de esta zona. 

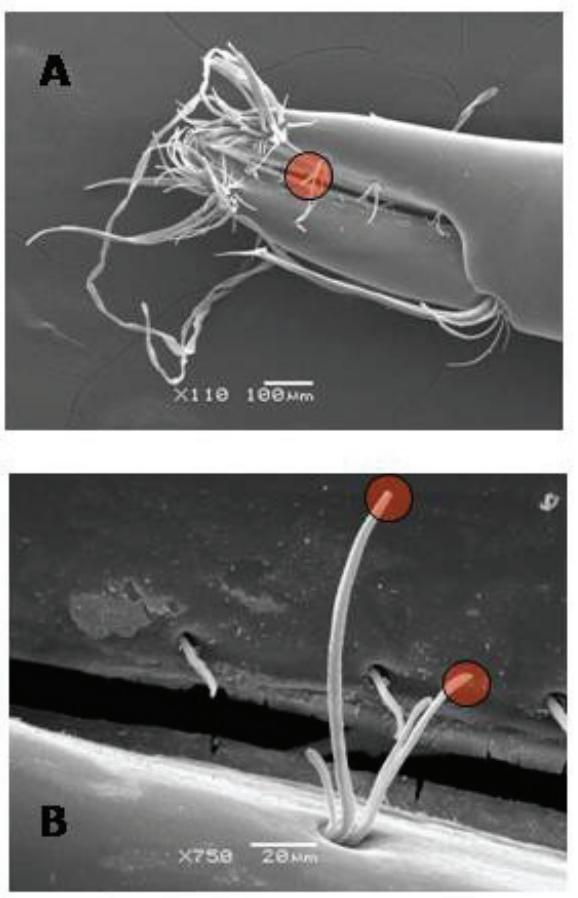

Figura 2. Análisis con MEB de: A, segundo pereiópodo de Barbouria yanezi; B, amplificación de las setas del borde interno del dactilo; C, acercamiento de la punta de la setas del propodio, y D, y E, acercamiento de la punta de las setas ubicadas en el dactilo.

Los resultados expuestos aquí para 2 especies anquihalinas que habitan las zonas más profundas de los cenotes de Cozumel demuestran que las adaptaciones progresivas van encaminadas a lograr una eficiencia alimentaria alta, considerando las condiciones del ambiente que estos animales ocupan. Por lo tanto, esas especializaciones en las setas aserradas, o bien, en los bordes cortantes de los pereiópodos quelados, junto con las pautas de comportamiento registradas, indican que la disponibilidad de alimento así como las altas concentraciones de bacterias que utilizan el ácido sulfhídrico $\left(\mathrm{H}_{2} \mathrm{~S}\right)$ y que se encuentran adheridas a las hojas depositadas por la selva son factores que inducen al desarrollo de adaptaciones progresivas.

En suma, en estas especies cavernícolas se ha
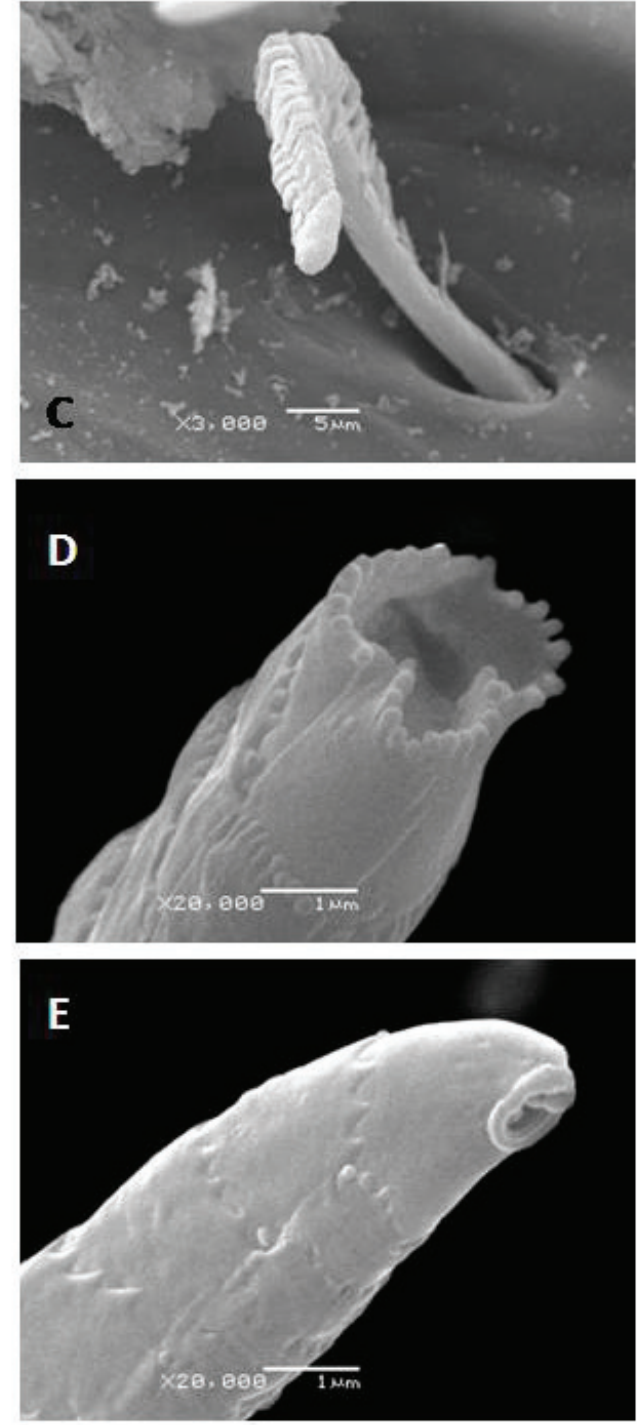

registrado una alta eficiencia alimentaria. Mientras que las especies de decápodos epigeos ocupan tiempo y energía en competir por diferentes recursos con sus coespecíficos, pues están adaptados a la abundancia de comida, los crustáceos estigobios, en contraste, debido precisamente a la escasez de alimento en las cuevas, jamás usan el tiempo ni la energía en pelear por comida alternativa, como se demostró en los resultados. Existen otras posibles explicaciones para el comportamiento no agresivo de los crustáceos cavernícolas, como puede ser la baja densidad poblacional que implica pocas posibilidades de encuentro. Sin embargo, las mismas pautas conductuales han sido registradas tanto para peces como para otros crustáceos (Abele y Felgenhauer, 1985; Wilkens, 1988). 


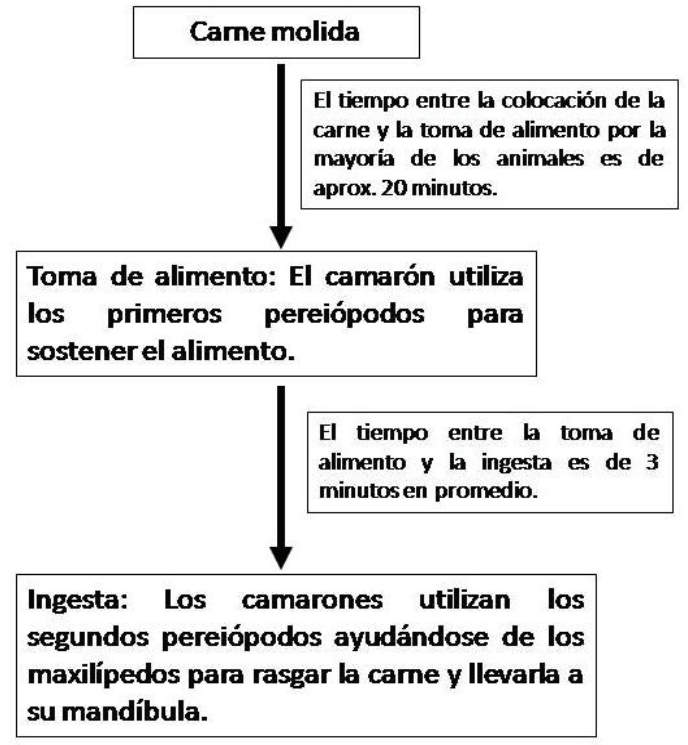

Figura 3. Pautas de comportamiento alimentario observadas en laboratorio para Barbouria yanezi.
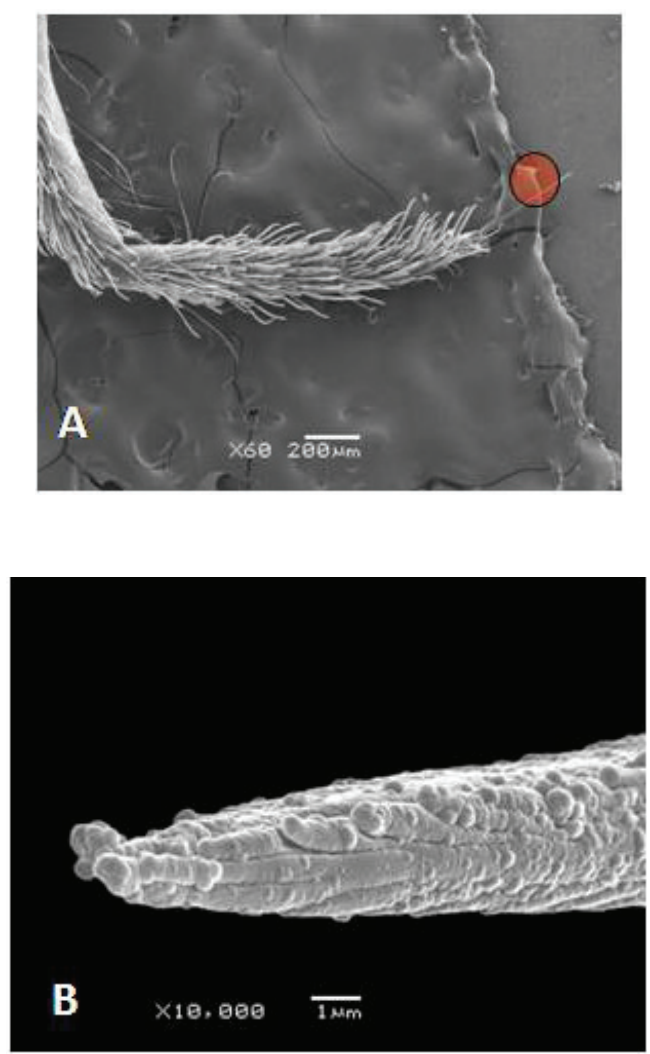
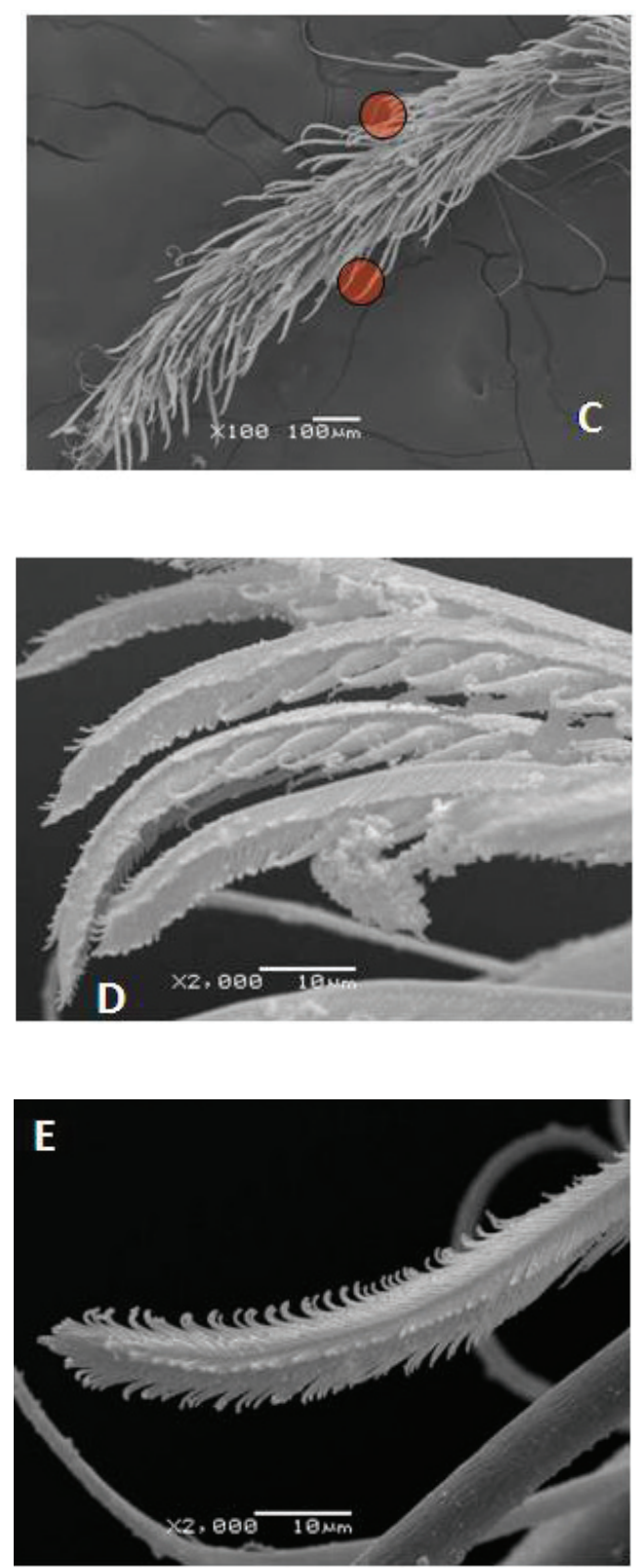

Figura 4. Análisis con SEM del dactilo del tercer maxilípedo de Agostocaris bozanici: A, tercer maxilípedo; B, amplificación de la punta; C, setas de la parte dorsal y ventral del dactilo; y D y E, acercamiento de la punta de las respectivas setas. 

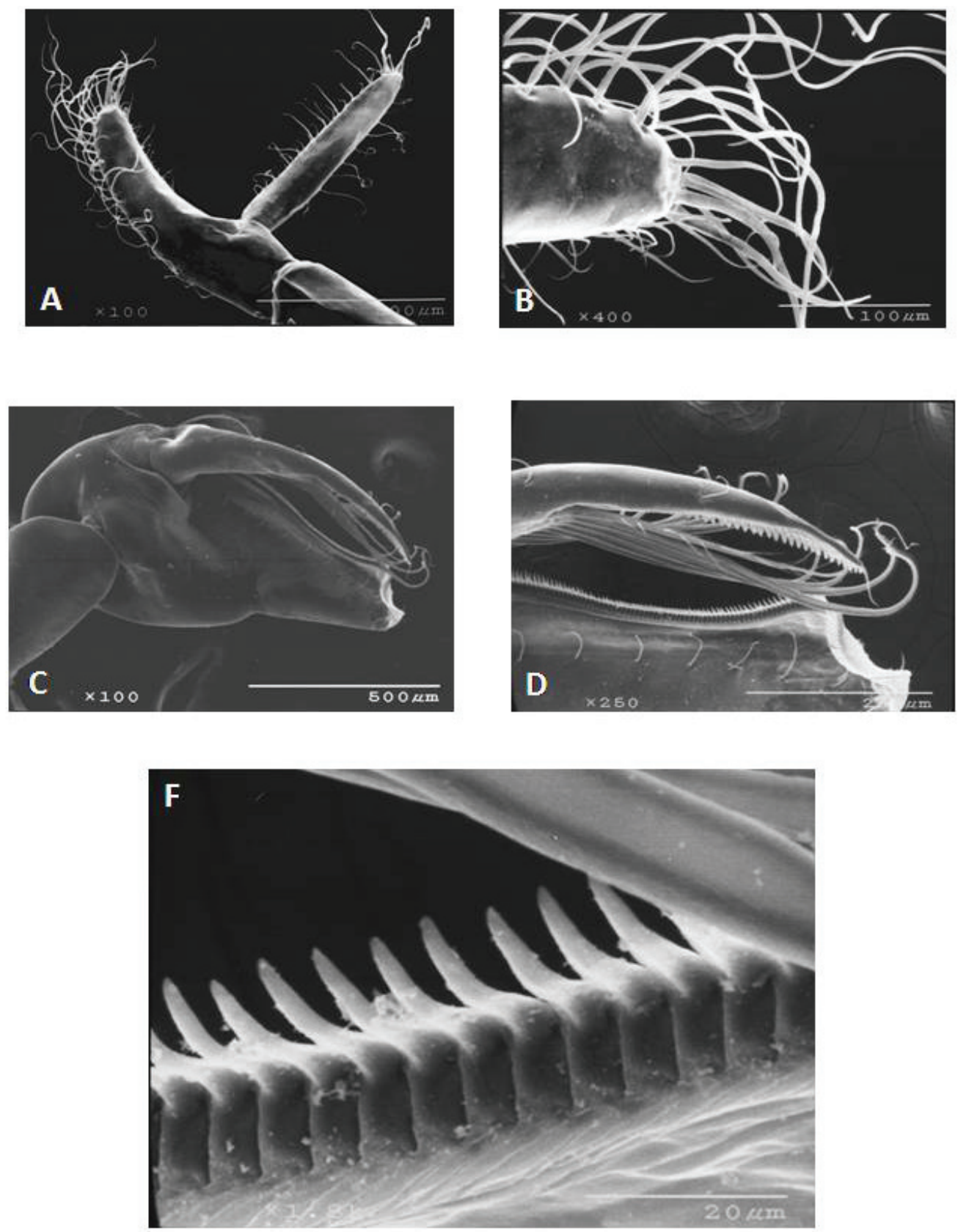

Figura 5. Análisis con MEB de: A, quela del segundo pereiópodo de Agostocaris bozanici; B, amplificación de la punta del dactilo; C, quela del primer pereiópodo; D, acercamiento de las setas del dactilo y E, amplificación del borde aserrado del propodio. 


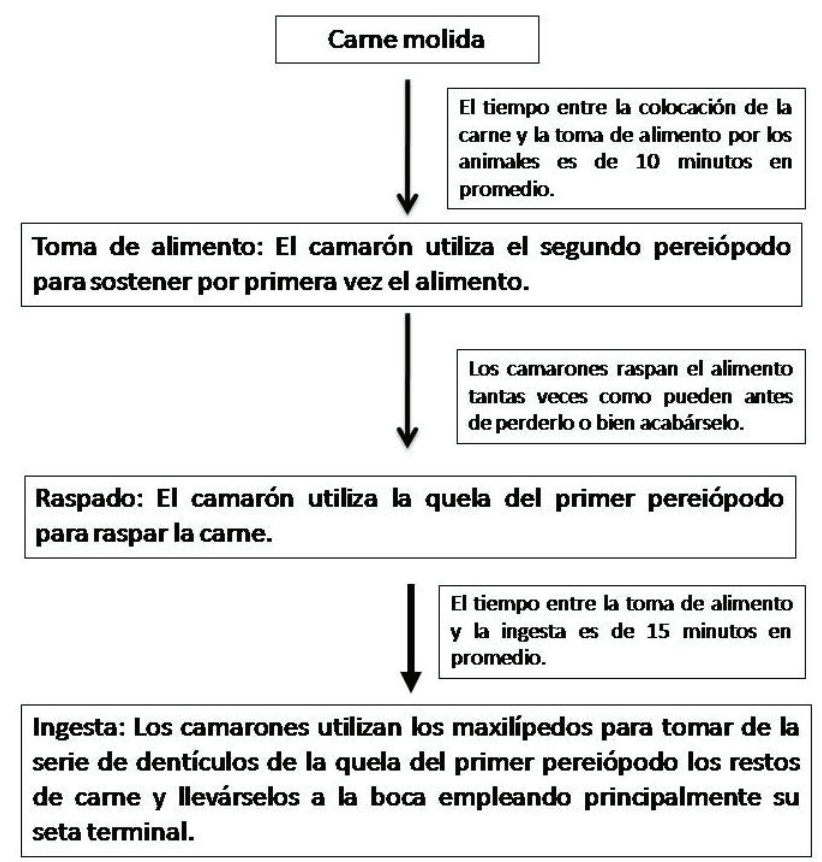

Figura 6. Pautas de comportamiento alimentario observadas en laboratorio para Agostocaris bozanici.

\section{Agradecimientos}

Este estudio es producto del proyecto "Los crustáceos cavernícolas de la isla de Cozumel" apoyado por PROMEPSEP y por la DDS de la UQROO-Cozumel. Se agradece A Germán Yáñez, el invaluable apoyo en campo y en la recolección de los organismos; a E. Zarza-González, su participación en el proyecto; a Jesús Campos y a Ángel Muñoz, su colaboración en las observaciones del laboratorio; a la Biól.Yolanda Hornelas (ICMyL-UNAM) y a la M.en C. Berenit Mendoza Garfias (IB-UNAM), por el apoyo en la realización de las micrografías.

\section{Literatura citada}

Abele, L. G. y B. E. Felgenhauer. 1985. Observations on the ecology and feeding behaviour of the anchialine shrimp Procaris ascensionis. Journal of Crustacean Biology 5:1524.

Allegrucci, G., F. Baldari, D. Cesaroni, R. S. Thorpe y V. Sbordoni. 1992. Morphometric analysis of interspecific and microgeographic variation of crayfish from a Mexican cave. Biological Journal of the Linnean Society 47:455-468.

Banister, K. E. 1984. A subterranean population of Garra barreimiae (Teleostei: Cyprinidae) from Oman, with comments on the concept of regressive evolution. Journal of
Natural History 18:927-938.

Creaser, E. P. 1938. Larger cave Crustacea of the Yucatan Peninsula. In Fauna of the caves of Yucatan, Publication 491, A. S. Pearse (ed.). Carnegie Institution of Washington, Washington, D.C. 304 p.

Culver, D. C. 1982. Cave life: evolution and ecology. Harvard University Press, Cambridge, Massachussetts. 189 p.

Culver, D. C., T. C. Kane y D. W. Fong. 1995. Adaptation and natural selection in caves: The evolution of Gammarus minus. Harvard University Press, Cambridge, Massachussetts. 223 p.

Garm, A. 2004a. Revising the definition of the crustacean seta and setal classification systems based on examinations of the mouthpart setae of seven species of decapods. Zoological Journal of the Linnean Society 142:233-252.

Garm, A. 2004b. Mechanical functions of setae from the mouth apparatus of seven species of decapod crustaceans. Journal of Morphology 260:85-100.

Gillieson, D. 1996. Caves: processes, development and management. Blackwell, Oxford. 324 p.

Hobbs, H. H. Jr., H. H. Hobbs III y M. A. Daniel. 1977. A Review of the troglobitic decapod crustaceans of the Americas. Smithsonian Contributions to Zoology 244:1-154.

Hoffmann, A., J. G. Palacios-Vargas y J. B. Morales-Malacara. 1986. Manual de bioespeleología (con nuevas aportaciones de Morelos y Guerrero, México). Laboratorio de Acarología, Facultad de Ciencias, Universidad Nacional Autónoma de México, México, D.F. 274 p.

Hüppop, K. 1985. The role of metabolism in the evolution of cave animals. The National Speleological Society Bulletin, Special Issue Regressive Evolution 47:136-146.

Iliffe, T. M. 1986. The zonation model for the evolution of aquatic faunas in anchialine caves. Stygologia 2:2-9.

Iliffe, T. M. 1993. Fauna troglobia acuática de la península de Yucatán. In Biodiversidad marina y costera de México, S. I. Salazar-Vallejo y N. E. González (eds.). Comisión Nacional para el Conocimiento y Uso de la Biodiversidad / Centro de Investigaciones de Quintana Roo, Chetumal. p. 673-686.

Jefferson, G. T. 1976. Cave faunas. In The science of speleology, T. D. Ford y C. H. D. Cullingford (eds.). Academic, London. $593 \mathrm{p}$.

Jones, R., D. C. Culver y T. C. Kane. 1992. Are parallel morphologies of cave organisms the result of similar selection pressures? Evolution 46:353-365.

Kane, T. C. y R. C. Richardson. 1985. Regressive evolution: an historical perspective. Journal of Caves and Karst Studies 47:71-77.

Kellie, S., J. Greer y R. L. Cooper. 2001. Alterations in habituation of the tail flip response in epigean and troglobitic crayfish. Journal of Experimental Zoology 290:163-176.

Kensley, B. 1988. New species and records of cave shrimps from the Yucatan Peninsula (Decapoda: Agostocarididae and Hippolytidae). Journal of Crustacean Biology 8:688-699.

Li, H. y R. L. Cooper. 2001. Spatial familiarity in the blind cave crayfish, Orconectes australis packardi. Crustaceana 74:417423.

Li, H. y R. L. Cooper. 2002. The effect of ambient light on blind cave crayfish: social interactions. Journal of Crustacean 
Biology 22:449-458.

Lincoln, R. J., G. A. Boxshall y P. F. Clark. 1982. A dictionary of ecology, evolution and systematics. Cambridge University Press, London. 298 p.

Mejía-Ortíz, L. M. 2005. Adaptations to cave life in decapods from Oaxaca. Association for Mexican Cave Studies Bulletin 15. $170 \mathrm{p}$.

Mejía-Ortíz, L. M. 2008. Adaptaciones de los crustáceos a la vida subterránea. In Crustáceos de México: estado actual de su conocimiento, F. Álvarez y G. Rodríguez-Almaraz (eds.). Universidad Autónoma de Nuevo León, Monterrey. $522 \mathrm{p}$.

Mejía-Ortíz, L. y R. G. Hartnoll. 2005. Modifications of eye structure and integumental pigment in two cave crayfish. Journal of Crustacean Biology 25:480-487.

Mejía-Ortíz, L. M. y M. López-Mejía. 2005. Are there adaptation levels to cave life in crayfishes? Journal of Crustacean Biology 25:593-597.

Mejía-Ortíz, L. M. y R. G. Hartnoll. 2006. A new use for useless eyes in cave crustaceans. Crustaceana 79:593-600.

Mejía-Ortíz, L. M., R. G. Hartnoll y M. López-Mejía. 2006. Progressive troglomorphisms in ambulatory and sensorial appendages of stygobitic decapod crustaceans (Cambaridae and Palaemonidae) compared with their epigeal congeners from Oaxaca, Mexico. Journal of Natural History 40:255264.

Mejía-Ortíz, L. M., E. Zarza y M. López. 2008. Barbouria yanezi sp. nov., a new species of cave shrimp (Decapoda, Barbouriidae) from Cozumel Island, Mexico. Crustaceana 81:663-672.

Mejía-Ortíz, L. M., R. G. Hartnoll y M. López-Mejía (en prensa). The abbreviated larval development of Macrobrachium totonacum Mejia, Alvarez \& Hartnoll, 2003 (Decapoda, Palaemonidae), reared in the laboratory. Crustaceana.

Pearse, A. S. 1938. Fauna of the caves of Yucatan. Carnegie Institution of Washington. $309 \mathrm{p}$.

Poulson, T. L. y W. B. White. 1969. The cave environment. Science 165: 971-981.
Schmitter-Soto, J. J., F. A. Comín, E. Escobar-Briones, J. Herrera-Silveira, J. Alcocer, E. Suárez-Morales, M. ElíasGutiérrez, V. Díaz-Arce, L. E. Marín y B. Steinich. 2002. Hydrogeochemical and biological characteristics of cenotes in the Yucatan Peninsula (SE Mexico). Hydrobiologia 467:215-228.

Turk, S., B. Sket y S. Sarbu. 1996. Comparison between some epigean and hypogean populations of Asellus aquaticus (Crustacea: Isopoda: Asellidae). Hydrobiologia 337:161170.

Ueno, S. 1987. The derivation of terrestrial cave animals. Zoological Science 4:593-606.

Vogt, G. y J. Štrus. 1992. Oleospheres of the cave-dwelling shrimp Troglocaris shmidtii: a unique mode of extracellular lipid storage. Journal of Morphology 211:31-39.

Vogt, G. y J. Štrus. 1999. Hypogean life-style fuelled by oil. Naturwissenschaften 86:43-45.

Watson, J., E. Hamilton-Smith, D. Gillieson y K. Kiernan (eds.). 1997. Guidelines for Cave and Karst Protection. IUCN World Commission on Protected Areas (WCPA). Working Group on Cave and Karst Protection IUCN - The World Conservation Union, Gland. 30 p.

Wilkens, H. 1985. The evolution of polygenic systems, studied on epigean and cave populations of Astyanax fasciatus (Characidae, Pisces). Journal of Caves and Karst Studies 47:101-108.

Wilkens, H. 1988. Evolution and genetics of epigean and cave Astyanax fasciatus (Characidae, Pisces). Support for the Neutral Mutation Theory. Evolutionary Biology 24:271367.

Wilkens, H. 1992. Neutral mutations and evolutionary progress. In The Natural History of Biospeleology, A.I. Camacho (ed.). Museo Nacional de Ciencias Naturales / Consejo Superior de Investigaciones Científicas, Madrid. p. 402-422.

Yañez, G., E. Zarza-González y L. M. Mejía-Ortíz. 2008. Sistemas anquihalinos. In Biodiversidad acuática de la isla de Cozumel, L. M. Mejía-Ortíz (ed.). Plaza y Valdés, México, D. F. / Universidad de Quintana Roo, Cozumel. p. 49-69. 